\title{
Primary biliary cirrhosis and chronic active hepatitis: an examination of clinical, biochemical, and histopathological features in differential diagnosis
}

\author{
JMS WILLIAMSON,* DM CHALMERS, $\dagger$ AD CLAYDEN, $\ddagger$ MF DIXON, ${ }^{*}$ WSJ RUDDELL,$\dagger$ \\ MS LOSOWSKY†
}

From the University Departments of *Pathology, $†$ Medicine, and $\ddagger$ Community Medicine, Leeds

SUMMARY Seventy four liver biopsies from 59 patients were reviewed by two observers and histologically graded in the absence of clinical information, firstly, to assess the level of agreement with previous diagnoses; secondly, to identify differences between primary biliary cirrhosis and chronic active hepatitis; and, thirdly, to assess the specificity of Shikata orcein staining and antimitochondrial antibody positivity and titre for primary biliary cirrhosis. Thirty six patients with adequate histology were initially selected as typical of primary biliary cirrhosis or chronic active hepatitis; agreement both between observers and with original diagnoses was reached in 26 ( $72 \%$ ) (15 with primary biliary cirrhosis (group 1), 11 with chronic active hepatitis (group 2)). In 19 diagnostically difficult patients in whom clinical and original histological findings had been at variance, histological agreement between observers was reached in 17 (group 3) and original underdiagnosis of primary biliary cirrhosis was suggested. The main clinical and histological differences between groups 1 and 2 are discussed in this paper. Although a high grade of positivity for copper associated protein in the Shikata orcein stain was seen only in primary biliary cirrhosis, a high titre of antimitochondrial antibody positivity was not unique to this condition.

To establish the diagnosis in patients with chronic liver disease biochemical, immunological, and histopathological investigations are required, together with radiological proof of a patent biliary tree.' After an excessive intake of alcohol has been excluded the two most important causes of chronic liver disease in the United Kingdom are primary biliary cirrhosis and chronic active hepatitis.

Primary biliary cirrhosis is a disease of unknown aetiology, primarily affecting middle aged women, in which pruritus is often the first symptom. A serum antimitochondrial antibody is detected in over $80 \%$ of patients. ${ }^{23}$ The early histological changes are those of a chronic, non-suppurative, intrahepatic, destructive cholangitis. ${ }^{4}$ Its progression to cirrhosis has been divided into four histological stages, though in any biopsy more than one stage may be represented.' Thus although the diagnostic lesions,

Accepted for publication 15 May 1985 consisting of inflammatory destruction of large and medium sized interlobular bile ducts with the formation of paraductal granulomas (stage 1) may be seen at any time, they are most common early in the clinical course of the disease. In recent years Shikata orcein staining for copper associated protein has been claimed to assist in the diagnosis of primary biliary cirrhosis.

As the diagnostic duct lesion is focal and may be absent from needle biopsies a working diagnosis of primary biliary cirrhosis may depend on matching compatible histological appearances with the available clinical and immunological data. In this regard the presence of antimitochondrial antibodies has been found to be the most reliable indicator, ${ }^{6}$ but these antibodies are also found in some forms of chronic active hepatitis ${ }^{7}$ and in patients with nonspecific autoimmune disease. ${ }^{8}$

Many cases of chronic active hepatitis occur in young adult life, but the disease can occur at any time. It may follow treatment with drugs ${ }^{9}$ or viral hepatitis, ${ }^{10}$ or there may not be any obvious pre- 
Table 1 Histological variables and methods of grading

Portal tracts:

(1) Lymphocytes

Plasma cells

(2) Granulomas

Bile ducts:

(3) Loss of interlobular ducts

(4) Epithelial degeneration

(5) Atypical ductular proliferation

Parenchymal changes:

(6) Piecemeal necrosis

(7) Focal/spotty necrosis

(8) Bridging hepatic necrosis Final diagnosis

\begin{tabular}{ll} 
Normal & $\begin{array}{l}\text { Mild increase or } \\
\text { small aggregates }\end{array}$ \\
Absent & 1 \\
$\begin{array}{l}\text { Absent } \\
\text { Absent }\end{array}$ & $\begin{array}{l}\text { Reduced } \\
\text { Present }\end{array}$ \\
Absent & Mild \\
Absent & Mild \\
$\begin{array}{l}\text { Absent } \\
\text { Absent } \\
\text { Chronic active } \\
\text { hepatitis }\end{array}$ & $\begin{array}{l}\text { Mild } \\
\text { Mild } \\
\text { Primary biliary } \\
\text { cirrhosis }\end{array}$ \\
\hline
\end{tabular}

$\begin{aligned} & \text { Moderate increase or } \\ & \text { large aggregates }\end{aligned}$
Normal numbers
Moderate
Moderate
Moderate
Moderate
Uncertain

$\begin{aligned} & \text { Large increase or } \\ & \text { follicles } \\ & \text { Several }\end{aligned}$
Severe
Severe irregularity
in lobular
margin
Severe
Severe
Inadequate

Large increase or follicles Inadequate cipitating factor, in which case it is regarded as part of an autoimmune process." Rarely, cases are associated with $\alpha_{1}$-antitrypsin deficiency or Wilson's disease. Clinical and biochemical features overlap with those of primary biliary cirrhosis and antimitochondrial antibodies may be present, albeit usually in low titre. ${ }^{12}$ The histological features are piecemeal necrosis with formation of liver cell rosettes and fibrous expansion of portal areas with bile duct proliferation and chronic inflammatory cell infiltration. ${ }^{13}$ In severe forms diffuse liver cell injury is found with either single cell or bridging necrosis.

In response to the clinical impression that there is a group of patients with antimitochondrial antibodies, with some of the clinical features of primary biliary cirrhosis, and some of the histological features of chronic active hepatitis, which makes diagnosis difficult, we carried out an analysis of biopsy material from such patients and compared these biopsies with liver biopsies from two further groups of patients, who were regarded both clinically and pathologically as undoubtedly having primary biliary cirrhosis and chronic active hepatitis. The aims of the investigation were primarily to assess the level of agreement in the diagnosis of primary biliary cirrhosis and chronic active hepatitis on histological review; to identify the main clinical and histological differences between groups of confirmed cases of primary biliary cirrhosis and chronic active hepatitis; to compare the level of Shikata orcein staining in each group; and, finally, to assess the specificity of antimitochondrial antibodies for primary biliary cirrhosis.

\section{Material and methods}

Fifty nine patients were studied. They had been classified on the basis of clinical features and previous investigations into three groups consisting of those with typical primary biliary cirrhosis (18 patients, in whom investigation showed positivity for antimitochondrial antibody with consistent histol-ogy), those with typical chronic active hepatitis (21 patients, all negative for antimitochondrial antibody with characteristic histology), and 20 patients with antimitochondrial antibodies and previously reported histological features suggestive of chronic active hepatitis (the "doubtful" group). From these 59 patients 74 biopsies, including three obtained after death, were abstracted from the files. Forty five patients had one biopsy, 13 had two, and one had three. The material consisted mainly of needle biopsies with some wedge biopsies from which sections stained with haematoxylin and eosin, Perls's stain and a reticulin stain were available. The assembled

Table 2 Histological diagnosis after review

\begin{tabular}{|c|c|c|c|c|c|}
\hline Initial groups (n) & $\begin{array}{l}\text { Primary biliary } \\
\text { cirrhosis }\end{array}$ & $\begin{array}{l}\text { Chronic active } \\
\text { hepatitis }\end{array}$ & $\begin{array}{l}\text { Uncertain diagnosis } \\
\text { (mixed histological } \\
\text { pattern) }\end{array}$ & Inadequate & $\begin{array}{l}\text { No } \\
\text { agreement: }\end{array}$ \\
\hline \multirow{2}{*}{$\begin{array}{l}\text { Selected primary biliary } \\
\text { cirrhosis (18) } \\
\text { Selected chronic active } \\
\text { hepatitis (21) } \\
\text { "Doubtful" } \\
\text { antimitochondrial } \\
\text { antibody positive chronic } \\
\text { active hepatitis (20) }\end{array}$} & 15 & 3 & $\mathbf{0}$ & 0 & 0 \\
\hline & 13 & 11 & 3 & 3 & 3 \\
\hline
\end{tabular}


Table 3 Mitochondrial antibody titres according to diagnostic group

\begin{tabular}{llrl}
\hline & $<1 / 200$ & $\geqslant 1 / 200$ & Range \\
\hline Group: & & & 11 \\
1 (Primary biliary cirrhosis) & 4 & 0 & $1 / 40-1 / 800$ \\
2 (Chronic active hepatitis) & 0 & 9 & $1 / 100-1 / 800$ \\
3 (Reclassified as primary biliary cirrhosis) & 4 & 3 & $1 / 100-1 / 1600$ \\
(Reclassified as other than primary biliary cirrhosis) & 1 & 9 \\
\hline
\end{tabular}

material dated back to 1969 , so that only 45 of the 59 patients had Shikata orcein stains available on one or more of their biopsies.

Stored sera were available for nearly all patients, and antimitochondrial antibody titres were repeated by indirect immunofluorescence using cryostat sections cut from a composite block of rat kidney, liver, and stomach. Sera were initially screened at a dilution of $1 / 20$ using polyvalent fluorescein isothiocyanate conjugated sheep antihuman immunoglobulin (Wellcome) and thereafter diluted in saline to titres of $1 / 40,1 / 100,1 / 200,1 / 400,1 / 800$, and $1 / 1600$.

Biopsy material from each patient was randomised and presented consecutively to each of two experienced pathologists (MFD, JMSW), who, without knowledge of clinical data and using agreed criteria, individually allocated each biopsy to one of four categories; primary biliary cirrhosis, chronic active hepatitis, diagnosis uncertain (mixed), and inadequate for histological diagnosis if less than three well sectioned portal areas were available. After comparison of the histological diagnoses made by the observers with the original diagnoses the two groups of patients with confirmed primary biliary cirrhosis and chronic active hepatitis were identified.

The clinical variables recorded for each patient (at the time of initial diagnosis) were: sex, age, presence or absence of pruritis, jaundice, splenomegaly, and ascites. The biochemical variables were bilirubin concentration, alkaline phosphatase activity, alanine aminotransferase activity, albumin concentration, and globulin concentrations. Table 1 lists the histological features and grades used. When two or more adequate biopsies were available in the same patient the histological features and grade of Shikata orcein positivity were recorded in the earliest biopsy that was considered to show diagnostic features. When none of the biopsies seemed diagnostic these features were recorded in the earliest adequate biopsy.

\section{Results}

After eliminating four cases with inadequate biopsies the observers reached diagnostic agreement in 50 of the remaining 55 cases. Three from the group with typical primary biliary cirrhosis, however, were diagnosed as having chronic active hepatitis, and four from the group with typical chronic active hepatitis were rediagnosed (one with primary biliary cirrhosis and three with "mixed histological pattern"). In the 36 typical cases for which adequate material was available diagnostic agreement was reached between observers at review in $33(91 \%)$ and with original diagnoses in $26(72 \%)$, of which 15 were regarded as cases of confirmed primary biliary cirrhosis and 11 as cases of confirmed chronic active hepatitis (Table 2). These patients with histologically confirmed primary biliary cirrhosis and chronic active hepatitis were designated groups 1 and 2 , respectively.

Among 19 "doubtful" and diagnostically difficult patients for whom there was adequate material the observers reached agreement at review in 17. These 17 patients formed group 3 (Table 2). It was agreed that 13 of these patients showed the histological features of primary biliary cirrhosis, two the features of chronic active hepatitis, and two a mixed histological pattern. We compared the titres of antimitochon-

Table 4 Shikata orcein staining according to diagnostic group

\begin{tabular}{llll}
\hline & $\begin{array}{l}\text { Grade 0 } \\
\text { (Absent) }\end{array}$ & $\begin{array}{l}\text { Grades 1-3 } \\
\text { (Scanty, minor, moderate) }\end{array}$ & $\begin{array}{c}\text { Grade 4 } \\
\text { (Severe accumulation) }\end{array}$ \\
\hline $\begin{array}{l}\text { Group: } \\
\text { 1 (Primary biliary cirrhosis, } \mathrm{n}=13)\end{array}$ & 1 & 7 & 5 \\
2 (Chronic active hepatitis, $\mathrm{n}=9$ ) & 4 & 5 & 0 \\
3 (Reclassified as primary biliary cirrhosis, & 0 & 8 & 4 \\
$\begin{array}{l}\text { (Reclassified as other than primary biliary } \\
\text { cirrhosis (3)) }\end{array}$ & 1 & 2 & 0 \\
\hline
\end{tabular}

Two tailed Fisher's exact test based on absent or present staining in groups 1 and $2 ; p=0.06$. 
Table 5 Contingency tables of significant variables according to diagnostic group

\begin{tabular}{|c|c|c|c|c|c|c|}
\hline & \multicolumn{2}{|c|}{ Granuloma(s) } & \multicolumn{2}{|l|}{ Pruritus } & \multicolumn{2}{|c|}{ Alkaline phosphatase } \\
\hline & Absent & Present & Absent & Present & $\begin{array}{l}\leqslant 45 \mathrm{KAU} / 1 \\
\text { (normal) }\end{array}$ & $\begin{array}{l}>45 K A U / 1 \\
\text { (raised) }\end{array}$ \\
\hline \multirow{3}{*}{$\begin{array}{l}\text { Group } 1 \text { (primary biliary } \\
\text { cirrhosis) } \\
\text { Group } 2 \text { (chronic active } \\
\text { hepatitis) } \\
\text { Significance using Fisher's } \\
\text { exact test (two tailed) }\end{array}$} & 8 & 7 & 4 & 11 & 4 & 11 \\
\hline & 11 & 0 & 10 & 1 & 10 & 1 \\
\hline & \multicolumn{2}{|c|}{$p<0.02$} & \multicolumn{2}{|c|}{$p<0.01$} & \multicolumn{2}{|c|}{$p<0.01$} \\
\hline
\end{tabular}

drial antibody in the patients from group 3 with those from group 1 and classified them using a titre of $1 / 200$, which represents the mid point of the range (Table 3). Using Fisher's test, there was no significant difference between the titres in this group compared with those in the patients with primary biliary cirrhosis. Furthermore, a high titre $(\geqslant 1 / 200)$ of postitivity for antimitochondrial antibody was found in some patients from group 3 whose histological appearance was characteristic of chronic active hepatitis.

To assess the value of Shikata orcein staining we made a separate classification of staining grade by group (Table 4). This showed a predominance of staining in the middle of the range in each of the groups, though highly positive staining (grade 4) was not seen in group 2 patients with chronic active hepatitis. A two tailed Fisher's exact test based on absent or present staining in the groups with primary biliary cirrhosis and chronic active hepatitis closely approached significance $(p=0.05)$.

Subsequent analysis of the clinical, biochemical, and histological data on the patients from groups 1 and 2 resulted in identification of three variables that were found to be of value in differentiating primary biliary cirrhosis from chronic active hepatitis. These variables were raised activities of alkaline phosphatase, presence of pruritis, and formation of portal (or portal and parenchymal) granulomas. Table 5 shows the distribution of these variables between groups. Patients from group 1 also showed more pronounced changes in bile ducts than those from group 2, especially as regards loss of or reduction in interlobular bile ducts, but this difference did not reach formal significance, probably because of the small size of the sample.

\section{Discussion}

The results of this study again illustrate how difficult it is for histopathologists to make a precise diagnosis in some patients with chronic liver disease. The differential diagnosis of primary biliary cirrhosis from chronic active hepatitis is thought to present difficulty in up to $15 \%$ of unselected cases. ${ }^{14}$ Our findings (Table 2) show a high measure of agreement between observers especially in the histological diagnosis of primary biliary cirrhosis, but also emphasise that a diagnosis of chronic active hepatitis may be reached in a small proportion of cases previously regarded as primary biliary cirrhosis, both clinically and histologically, and vice versa. With a selected population of patients with typical primary biliary cirrhosis and chronic active hepatitis review of the histology produced agreement on these diagnoses (albeit with use of agreed criteria) in $83 \%$ of those with adequate biopsies. Only $72 \%$ of the review diagnoses, however, corresponded to the original diagnoses. After inclusion of the diagnostically difficult group agreement on primary biliary cirrhosis and chronic active hepatitis at review remained high at $82 \%$ but overall agreement with the original diagnosis fell to $51 \%$, due to the initial underdiagnosis of primary biliary cirrhosis.

Among the histological variables reported to be of value in the differential diagnosis of primary biliary cirrhosis from chronic active hepatitis are irregular fibrosis and scarring, portal parabiliary granulomas, ${ }^{14}$ discrete septal lymphocytic aggregates, paucity of interlobular bile ducts with atypical bile duct proliferation, periseptal swelling and cholestasis of liver cells, ${ }^{15}$ and, in the early stages, positive periportal orcein staining for copper associated protein. ${ }^{16}$

In the diagnosis of chronic active hepatitis appreciable piecemeal necrosis and severe lobular liver cell damage with bridging hepatic necrosis have been regarded as valuable histological findings. ${ }^{17}$ Destructive duct lesions may be seen in cases of chronic active hepatitis ${ }^{18}$ and non-A non-B hepatitis. ${ }^{19}$ Lesions combining epithelial rupture, fibrosis, and parabiliary granuloma formation, however, are virtually specific for primary biliary cirrhosis..$^{20}$ Our experience is that degenerative duct lesions are uncommon in chronic active hepatitis. Only one case of chronic active hepatitis showed epithelial degenerative ductal change without pericholangitis, fibrosis, or scarring, and a further patient showed scarring of the portal area at the site of interlobular 
ducts without pericholangitis. In contrast, four of the 15 patients with primary biliary cirrhosis showed epithelial destruction and others showed vacuolation of intact bile duct epithelial cytoplasm without inflammatory exudate. Although epithelial degeneration as part of the diagnostic duct lesion has been reported at all stages of primary biliary cirrhosis, it is seen most frequently at an early stage. ${ }^{5}$ The low incidence of ductal lesions in this study probably reflects the relatively late stage of the patients at the time of biopsy.

Formation of portal granulomas was specific for primary biliary cirrhosis in this series (Table 5) but was present in only half of all cases and was apparently not invariably either parabiliary or associated with destructive duct lesions. It may be, however, that isolated portal granulomas mark the site of destroyed small and medium sized interlobular bile ducts, much as aggregates of lymphocytes do in stage 2 of primary biliary cirrhosis. ${ }^{17}$

Absence of medium sized interlobular bile ducts was a specific finding for primary biliary cirrhosis. In all cases at least three well sectioned, representative portal areas were examined. Absence of bile ducts was seen in five cases of primary biliary cirrhosis (out of 15), but none of the patients with chronic active hepatitis showed such an appearance. Reduction and loss of bile ducts are recognised as an early feature of primary biliary cirrhosis. ${ }^{14}$

No significant differences were found in parenchymal appearances between the groups with primary biliary cirrhosis and chronic active hepatitis. This is an unexpected finding and might reflect the relatively advanced stage of the patients with primary biliary cirrhosis at the time of biopsy. Primary biliary cirrhosis has a long preclinical phase, ${ }^{11}$ and the changes are confined to portal areas only in the early stages.

Our analysis also confirmed one well known clinical factor (pruritus), and one well known biochemical factor (raised alkaline phosphatase activity) that are of value in differentiating primary biliary cirrhosis and chronic active hepatitis. These variables may not be independent. Pruritus occurred in two thirds of the patients with primary biliary cirrhosis but in only one of the patients with chronic active hepatitis (who lacked antimitochondrial antibodies but whose alkaline phosphatase activity was raised). Other workers have commented on the importance of pruritus in the diagnosis of primary biliary cirrhosis $^{11}$ as it often predates other symptoms and brings the patient to medical attention.

Histological review of our patients from group 3 showed that the group consisted mainly of patients with primary biliary cirrhosis, and this finding supports observations that there is a tendency to over- diagnose chronic active hepatitis and underdiagnose primary biliary cirrhosis. ${ }^{14}$ A cholestatic, antimitochondrial antibody positive group of patients with chronic active hepatitis has been described by several authors. ${ }^{5722}$ We think, however, that most of the patients who on initial biopsy are histologically classified as cases of chronic active hepatitis but who have positive antimitochondrial antibodies will ultimately turn out to have primary biliary cirrhosis, based on their clinical pattern and histological review.

Antimitochondrial antibody status was not included among variables in our statistical analysis because its presence or absence was one of the factors used to define two of the groups, but others have found that in difficult cases it is of little value in differentiating primary biliary cirrhosis from chronic active hepatitis. ${ }^{21}{ }^{23}$ Some authors have suggested that specificity for primary biliary cirrhosis increases as the titre rises. ${ }^{24}$ Although this usually held good in our patients, we found that of four doubtful patients classified as "other than primary biliary cirrhosis" at histological review, three had titres of $\geqslant 1 / 200$ and, furthermore, four of 15 patients with primary biliary cirrhosis had a titre of $<1 / 200$ (Table 3 ). Thus a high titre of antimitochondrial antibody is found in some patients who do not show the histological features of primary biliary cirrhosis on biopsy and fails to identify all those with this histological diagnosis.

Some authors regard Shikata orcein staining as helpful in the precirrhotic stages of primary biliary cirrhosis and chronic active hepatitis, ${ }^{25}{ }^{26}$ but we were surprised to find that the amount of positivity for orcein in this study was not among the most reliable variables for differentiating primary biliary cirrhosis from chronic active hepatitis. Scanty to moderate accumulation of copper associated protein (Table 5) was seen in cases of both primary biliary cirrhosis and chronic active hepatitis, so the test seems to lack sensitivity and specificity. In our study orcein staining was positive in $92 \%$ of cases of primary biliary cirrhosis and in $55 \%$ of cases of chronic active hepatitis, corresponding to previous findings of British authors ${ }^{27}$ and contrasting with those of Swedish authors, ${ }^{25}$ who reported that cases of chronic active hepatitis failed to stain. We agree with suggestions that the value of Shikata orcein staining lies mainly in strongly positive and absent staining (Table 5).$^{16}$ More than $30 \%$ of our cases of primary biliary cirrhosis but none of our cases of chronic active hepatitis were strongly positive. Forty five per cent of cases of chronic active hepatitis were negative for deposition of copper associated protein but only $8 \%$ of cases of primary biliary cirrhosis.

The problem of differentiating primary biliary cirrhosis from chronic active hepatitis is likely to 
remain difficult. The diagnosis of primary biliary cirrhosis is straightforward if characteristic duct lesions are present, but these are often seen only early in the clinical course. Later, differentiation of primary biliary cirrhosis from chronic active hepatitis requires careful consideration of all the available information. We sought to identify variables of value in discriminating the difficult cases of primary biliary cirrhosis from chronic active hepatitis but would concede that the variables were selected from only a small population of patients. We confirm that stains for copper associated protein are of the most diagnostic value early in the clinical course of primary biliary cirrhosis when they are positive, and we suspect that high titres of antimitochondrial antibodies are occasionally seen in chronic active hepatitis. We also suspect that there is a considerable tendency to underdiagnose primary biliary cirrhosis histologically in "difficult" patients because in the later stage of the disease the distinguishing features are more subtle and there is a greater overlap with the changes caused by chronic active hepatitis.

If confirmed prospectively our results imply that for the histopathologist consideration of ductal and portal changes rather than architectural and parenchymal changes, together with evaluation of Shikata orcein staining, is most likely to provide a useful opinion. For the clinician the presence or absence of pruritus and raised activities of alkaline phosphatase, together with exclusion of causes for chronic active hepatitis, are important. The value of positive antimitochondrial antibodies and their titre in difficult cases is still in dispute.

We thank Dr G Hardy for allowing access to histological material, and Miss $\mathrm{H}$ Swiercz and Mrs JC Fearnley for secretarial help.

\section{References}

' Losowsky MS. Primary biliary cirrhosis. Medicine 1978; 17:884-6.

${ }^{2}$ Doniach D. The concept of 'autoallergic' hepatitis. Proceedings of the Royal Society of Medicine 1970;63:527-31.

${ }^{3}$ Sherlock S, Scheuer PJ. The presentation and diagnosis of 100 patients with primary biliary cirrhosis. N Engl J Med 1973; 289:674-8.

4 Rubin E, Schaffner F, Popper H. Primary biliary cirrhosis. Chronic non-suppurative destructive cholangitis. Am J Pathol 1965;46:387-408.

s Hadziyannis S, Scheuer PJ, Feizi T, Naccarato R, Doniach D, Sherlock S. Immunological and histological studies in primary biliary cirrhosis. J Clin Pathol 1970;23:95-8.

- Goudie RB, MacSween RNM, Goldberg DM. Serological and histological diagnosis of primary biliary cirrhosis.J Clin Pathol
1966; 19:527-38.

' Jones WA, Tisdale WA. Posthepatitic cirrhosis clinically simulating extrahepatic biliary obstruction (so-called 'primary biliary cirrhosis'). N Engl J Med 1963;268:629-39.

${ }^{8}$ Maas D, Schubothe H. Ein lupus-erythematodes-ahnliches Syndrom mit antimitochondrialen Antikorpern. Dtsch Med Wochenschr 1973;98:131-9.

• Goldstein GB, Lam KC, Mistilis SP. Drug induced active chronic hepatitis. Am J Dig Dis 1973;18:177-84.

${ }^{10}$ Dudley FJ, Scheuer PJ, Sherlock S. Natural history of hepatitisassociated antigen-positive liver disease. Lancet 1972;ii: 1388-93.

"Sherlock S. Diseases of the liver and biliary system. 6th ed. Oxford: Blackwell Scientific Publications, 1981.

${ }^{12}$ Hamblin TJ. Significance of antimitochondrial antibodies. Lancet 1981;ii:1411-2.

${ }^{13}$ De Groote J, Desmet VJ, Gedigk P, et al. A classification of chronic hepatitis. Lancet 1968;ii:626-8.

${ }^{14}$ MacSween RNM. Pathology of the liver. Edinburgh: Churchill Livingstone, 1979.

is Wight DGD. Atlas of liver pathology. Lancaster: MTP Press, 1982.

${ }^{16}$ Guarascio P, Yentis F, Cerikbas U, Portmann B, Williams R. Value of copper-associated protein in diagnostic assessment of liver biopsy. J Clin Pathol 1983;36:18-23.

${ }^{17}$ Scheuer PJ. Liver biopsy interpretation. 3rd ed. London: Baillière-Tindall, 1980.

${ }^{18}$ Poulsen H, Christoffersen P. Abnormal bile duct epithelium in chronic aggressive hepatitis and cirrhosis. A review of morphology and clinical, biochemical and immunologic features. Hum Pathol 1972;3:217-25.

${ }^{19}$ Schmid M, Pirovino M, Altorfer J, Gudat F, Bianchi L. Acute hepatitis non-A non-B; are there any specific light microscopic features? Liver 1982;2:61-7.

${ }^{20}$ Christoffersen P, Poulsen H, Scheuer PJ. Abnormal bile duct epithelium in chronic active hepatitis and primary biliary cirrhosis. Hum Pathol 1972; 3:227-35.

${ }^{21}$ Solberg HE, Skrede S, Blomhoff JP. Diagnosis of liver disease by laboratory results and discriminant analysis. Identification of best combinations of laboratory tests. Scand J Clin Lab Invest 1975;35: 713-21.

22 Kloppel G, Seifert G, Lindner H, Dammermann R, Sack HJ, Berg PA. Histopathological features in mixed types of chronic aggressive hepatitis and primary biliary cirrhosis. Correlation of liver histology with mitochondrial antibodies of different specificity. Virchows Arch [Pathol Anat] 1977;373:143-60.

${ }^{23}$ Triger DR, Charlton CAC, Milford-Ward A. What does the antimitochondrial antibody mean? Gut 1982;23:814-8.

${ }^{24}$ Hodges JR, Hall AJ, Wright R. Primary biliary cirrhosis and antimitochondrial antibodies. Lancet 1981;ii:362.

${ }^{25}$ Vyberg M, Thomsen P. Orcein positive granules in liver cells. Acta Pathol Microbiol Scand 1979;87:421-5.

${ }^{26}$ Salaspuro M, Sipponen P. Demonstration of an intracellular copper-binding protein by orcein staining in long-standing cholestatic liver diseases. Gut 1976;13:787-90.

${ }^{27}$ Jain S, Scheuer PJ, Archer B, Newmann SP, Sherlock S. Histological demonstration of copper and copper-associated protein in chronic liver diseases. J Clin Pathol 1978;31:784-90.

Requests for reprints to: Dr MF Dixon, University Department of Pathology, University of Leeds, Leeds, LS2 9JT, England. 